\title{
Увеличение удельной поверхности углерод-содержащего сорбента путем введения дополнительных компонентов
}

\author{
Горелова Е.И., Котов В.В., Горелов И.С., Данилова Г.Н. \\ Воронежский государственный аграрный университет им. императора Петра I
}

Поступила в редакцию 7.02.2018 г.

DOI: https://doi.org/10.17308/sorpchrom.2018.18/536

Синтезирован сорбент БАКС-001 на основе наночастиц углерода, диоксида кремния и серебра. Для повышения сорбционных свойств композита были внесены дополнительные компоненты в рецептуру исходного материала. Получены новые сорбенты БАКС-002 путем введения в состав базового композита сульфата железа и БАКС-003 - сульфированием концентрированной серной кислотой. Установлен двухступенчатый характер изотерм сорбции бутанола, обусловленный наличием в структуре композитов двух частей с различной степенью дисперсности. Выявлено увеличение удельной поверхности, а также повышение сорбционных способностей в ряду композитов БАКС-001< БАКС-002 < БАКС-003.

Ключевые слова: удельная поверхность, сорбция, новые сорбенты, наночастицы, сульфирование, сульфат железа, бутанол.

\section{Increase in the specific surface area of the carbon-containing sorbent by introducing additional components}

\author{
Gorelova E.I., Kotov V.V., Gorelov I.S., Danilova G.N. \\ Voronezh State Agricultural University Named after The Emperor Peter the First
}

\begin{abstract}
The sorbent BAKS-001 on the basis of nanoparticles of carbon and silicon dioxide was synthesized. To increase the sorption properties of the composite, additional components were added to the formulation of the starting material.

The sorbent BAKS-001 was obtained by combining an anhydrous precipitate of silica with coal BAU, dehydrated at $150^{\circ} \mathrm{C}$ and ground at colloid mill, together with silver nanoparticles obtained by treatment of glucose with an ammoniacal solution of silver hydroxide in a solution of starch. The obtained clay mixture was granulated, dried and calcined at $750-800^{\circ} \mathrm{C}$.

New sorbents of BAKS-002 were obtained by introducing iron sulfate and BAKS-003 into the composition of the base composite by sulfonation with concentrated sulfuric acid. The sorbents were studied by the method of electron microscopy and the stalagmantry method of analysis.

The two-step character of isotherms of sorption of butanol due to the presence in the structure of composites of two parts with different degrees of dispersion was established.

An increase in the specific surface in the series of composites of BAKS-001 $<$ BAKS-002 $<$ BAKS003 (respectively $938<954<1008 \mathrm{~m} 2 / \mathrm{g}$ ), as well as an increase in the sorption capacity has been revealed which is characterized by the amount of the limiting specific sorption at both stages of sorption (respectively $5.18<5.27<5.57 \mathrm{mmol} / \mathrm{g}$ ).
\end{abstract}

Keywords: specific surface, sorption, new sorbents, nanoparticles, sulfonation, iron sulfate, butanol. 


\section{Введение}

Антропогенное загрязнение подземных вод и открытых водоемов, особенно в городах с развитой промышленностью, достигает катастрофических масштабов. Для решения этой проблемы необходима разработка новых методов очистки воды. Перспективным направлением является сорбционная очистка воды. В настоящее время широкое распространение получили модифицирование природных материалов [1] и разработка новых синтетических композитов [2]. При разработке синтеза новых эффективных сорбентов желательно, чтобы их свойства обеспечивали комплексное извлечение из воды вредных примесей неорганического, органического и микробиологического происхождения. При этом важнейшей задачей является установление особенностей структуры, физико-химических свойств этих сорбентов, а также механизмов сорбции на них веществ различной химической природы.

Нами с целью эффективного удаления из вод примесей различного характера разработана технология получения ряда композитных сорбентов (БАКС-001, БАКС002 и БАКС-003) [3-5]. Сорбент БАКС-001 получали совмещением обезвоженного при $150^{\circ} \mathrm{C}$ и измельченного на коллоидной мельнице аморфного осадка диоксида кремния с измельченным углем БАУ, а также с наночастицами серебра, полученного обработкой глюкозой аммиачного раствора гидроксида серебра в растворе крахмала. Полученную глинообразную смесь высушивали и прокаливали при 750-800 ${ }^{\circ} \mathrm{C}$. Получение сорбента БАКС-002 включало те же операции, однако, в глинообразную массу ингредиентов добавляли 20\% -ный раствор $\mathrm{FeSO}_{4}$, высушивали, прокаливали и отмывали от избытка соли сначала раствором $\mathrm{HCl}$, затем дистилированной водой. При синтезе сорбента БАКС-003 сначала уголь БАУ обрабатывали концентрированной $\mathrm{H}_{2} \mathrm{SO}_{4}$ в течение 24 часов, затем совмещали с силикатом натрия и далее проводили операции, как показано выше. Следует отметить, что при обработке БАУ серной кислотой проходило увеличение его объема примерно в 1.5 раза, что, повидимому, связано с набуханием вследствие сульфирования ароматических фрагментов, являющихся одними из компонентов активированного угля [6,7], образование фиксированных сульфогрупп и их гидратацией выделяющимися молекулами воды. Далее повторялись те же операции, что и при получении БАКС-001. Образцы полученных сорбентов подвергались электронномикроскопическому исследованию на электронном растровом микроскопе JEOL JSM6510-LV с энергодисперсионной приставкой Bruker, для определения элементного состава.

В зависимости от условий синтеза сорбенты имели различную степень дисперсности с преобладанием наночастиц (рис.1), с ее увеличением в ряду БАКС-001 < БАКС-002 < БАКС-003

На рисунке 1 показаны электронные фотографии сорбентов.

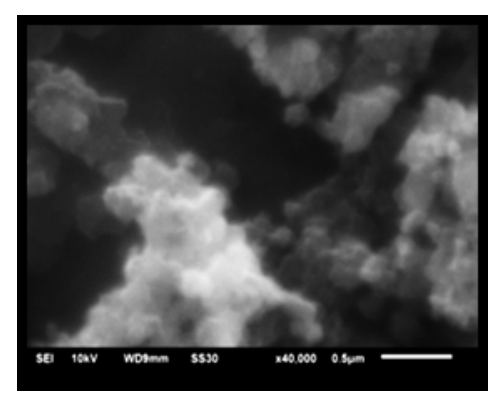

a

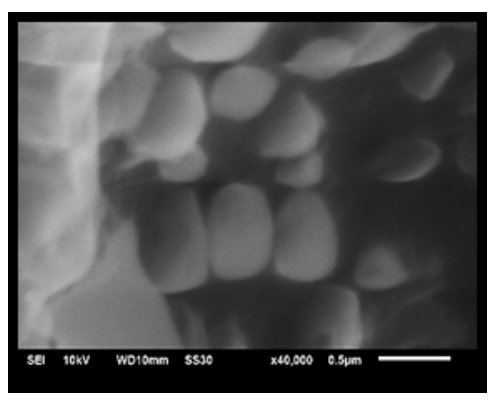

6

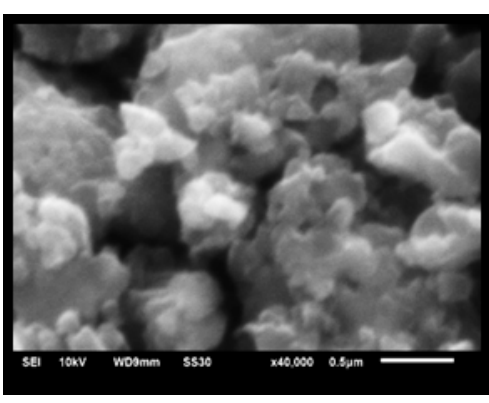

B

Рис. 1 Электронные фотографии сорбентов БАКС-001(а), БАКС-002(б), БАКС-003(в). Увеличение в 40000 раз. 
Химический состав полученных композитов позволяет предположить наличие в их строении активных центров различной полярности, а, следовательно, проявления селективности к сорбатам за счет как диполь-дипольных, так и дисперсионных взаимодействий. Такие взаимодействия характерны для дифильных органических соединений, каковыми являются алифатические спирты, в частности, бутанол.

\section{Эксперимент}

Сорбционная способность полученных композитов к дифильным органическим веществам с одновременным определением удельной поверхности исследовалось по методике, изложенной в работе [7]. Образцы сорбентов массой 5 г помещались в раствор объемом $200 \mathrm{~cm}^{3}$ с рядом концентраций в пределах 0.05-0.5 моль/дм ${ }^{3}$ при $20^{\circ} \mathrm{C}$ и приводились в равновесие в течение 24 часов. Затем по калибровочному графику «поверхностное натяжение-концентрация бутанола», построенному по данным сталагмометрического анализа исходных растворов, определялась концентрация бутанола в равновесных растворах. Удельная сорбция бутанола (Г) рассчитывалась по формуле:

$$
\Gamma=\frac{C_{0}-C}{C_{0}} \cdot V,
$$

где $\mathrm{C}_{0}$ и $\mathrm{C}$ - соответственные исходная и равновесная концентрации бутанола, $\mathrm{V}$ - объем раствора, $\mathrm{m}$ - масса сорбента.

По полученным данным строили изотермы сорбции, анализом которых в соответствии с использованием линейной формы уравнения Ленгмюра находили пре-

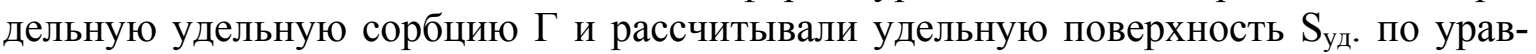
нению:

$$
S_{y d}=\Gamma_{\infty} \cdot N_{a} \cdot S_{c n}
$$

где $\mathrm{N}_{\mathrm{a}}$ число Авогадро, $\mathrm{S}_{\text {сп }}$ - площадь, занимаемая одной молекулой спирта $\left(0.3 \mathrm{HM}^{2}\right)[6]$.

\section{Обсуждение результатов}

На рис. 2 показаны изотермы сорбции бутанола на исследуемых сорбентах. Общей для всех композитов особенностью является двухступенчатый характер изотерм с четко выраженным разделением ступеней. Однако высота этих ступеней неодинакова, что исключает механизм двойной сорбции. По-видимому, данный характер кривых указывает на наличие в структуре сорбентов двух частей, различных по степени дисперсности. Первая ступень изотермы соответствует заполнению активных центров в более доступных, менее дисперсных участках, а вторая в более дисперсных.

Каждая из ступеней изотерм была проанализирована с использованием линейной формы уравнения Ленгмюра с выявлением предельной удельной сорбции $\left(\Gamma_{\infty}\right)$ и коэффициентов селективности $(К)$. При этом исходная равновесная концентрация бутанола для второй ступени определялась по величине $\Gamma_{\infty}$ на первой ступени и при анализе данных второй ступени принимались за нуль, а удельная сорбция рассчитывалась как разница между экспериментальными данными и $\Gamma_{\infty}$ на первой ступени. Линейные зависимости $\mathrm{C} / \Gamma-\mathrm{C}$ характеризовались достаточно высокими коэффициентами корреляции $\left(\mathrm{R}^{2} \sim 0.98\right)$. 


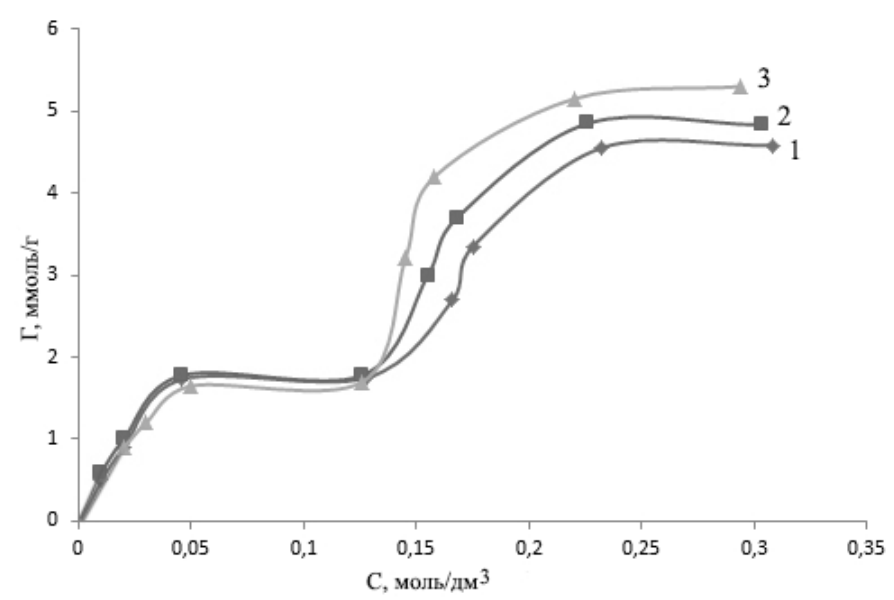

Рис. 2. Изотермы сорбции бутанола на образцах композитов 1 - БАКС-001,. 2 - БАКС-002, 3 - БАКС-003

Удельная поверхность сорбента достаточно высока и согласуется с этим показателем для активированного угля [6]. При этом модифицированный сорбент БАКС-003 по сравнению с другими обладает повышенной удельной поверхностью, что соответствует электронномикроскопическим данным (рис. 1).

Параметры сорбции и удельная поверхность композитов, вычисленная по сумме предельной сорбции на обеих ступенях $\Gamma_{\infty}$, показаны в табл. 1.

Таблица 1. Параметры сорбции бутанола на композитах и их удельная поверхность

\begin{tabular}{|c|c|c|c|c|c|c|}
\hline \multirow[b]{2}{*}{ Композит } & \multicolumn{3}{|c|}{$\Gamma_{\infty}$, ммоль $/ \Gamma$} & \multicolumn{2}{|c|}{ К, г/ммоль } & \multirow{2}{*}{$\begin{array}{c}\text { Удельная } \\
\text { поверхность, } \\
\text { м }^{2} / \Gamma\end{array}$} \\
\hline & 1 ступень & 2 ступень & $\Sigma \Gamma_{\infty}$ & 1 ступень & 2 ступень & \\
\hline БАКС-001 & 2.06 & 3.12 & 5.18 & 51 & 38 & 938 \\
\hline БАКС-002 & 2.09 & 3.18 & 5.27 & 53 & 57 & 954 \\
\hline БАКС-003 & 2.09 & 3.48 & 5.57 & 40 & 93 & 1008 \\
\hline
\end{tabular}

Предельная удельная сорбция на первой ступени изотерм практически одинакова для всех трех композитов, однако на второй ступени наблюдается различие в величине этого показателя. При этом на второй ступени, в отличие от первой, имеют место резкое увеличение коэффициента селективности в ряду БАКС-001<БАКС$002<$ БАКС-003. Отмеченные особенности связанны с топохимией и механизмом сорбционного процесса. Рассмотрим возможные варианты сорбции бутанола на активных центрах композитов. Состав сорбентов БАКС, в основном, включает активированный уголь с примерно 10\%-ной добавкой неорганических компонентов. На угле бутанол сорбируется в основном вследствие дисперсионных взаимодействий с ним углеводородного радикала. На силикатной части сорбентов проявление таких взаимодействий практически исключено из-за полярных связей в сорбенте. Однако сорбция бутанола как на модифицированных образцах (БАКС-002 и, особенно, БАКС-003), так и на силикатной части БАКС-001, возможна вследствие дипольдипольных взаимодействий спирт-сорбент. В принципе, выявить вклад каждого из видов взаимодействий практически невозможно, однако возможно определить вклад в общий сорбционный процесс ионообменной составляющей.

В работах $[4,5]$ нами установлены закономерности сорбции ионов $\mathrm{Fe}^{3+}$ на исследуемых композитах, показано наличие у них катионообменной функции и предложен механизм сорбции ионов железа на силикатной основе сорбента. Однако данные рис. 2 и табл. 1 указывают, что в случае модифицированных сорбентов и, в осо- 
бенности БАКС-003, увеличиваются сорбционные параметры процесса, а следовательно сильнее проявляются диполь-дипольные взаимодействия спирт-сорбент, что позволяет предположить и повышение катионообменных свойств. Для обоснования этого вывода нами использованы ранее полученные результаты $[4,5]$. Сравнительные данные приведены в таблице 2.

Таблица 2. Соотношение между сорбционными и катионообменными свойствами композитов (1 ступень сорбции).

\begin{tabular}{|c|c|c|c|c|}
\hline Сорбент & $\Gamma_{\infty \mathrm{Fe}}$ & $\mathrm{K}_{\mathrm{Fe}}$ & $\Gamma_{\infty \mathrm{Fe}} / \Gamma_{\infty \text { cп }}$ & $\mathrm{K}_{\mathrm{Fe}} / \mathrm{K}_{\mathrm{cп}}$ \\
\hline БАКС-001 & 0.96 & 57 & 0.47 & 1.12 \\
\hline БАКС-002 & 1.27 & 143 & 0.61 & 2.72 \\
\hline БАКС-003 & 2.14 & 332 & 1.02 & 8.43 \\
\hline
\end{tabular}

$\Gamma_{\infty}$ Fе и $\Gamma_{\infty}$ сп $\mathrm{K}_{\mathrm{Fe}}$ и $\mathrm{K}_{\text {сп }}$ - соответственно предельная удельная сорбция и коэффициент селективности композитов при сорбции ионов $\mathrm{Fe}^{3+}$ и молекул бутанола. В расчете соотношения данных для сорбции ионов железа и бутанола использованы данные таблицы 1.

Результаты показывают, что в ряду БАКС-001<БАКС-002<БАКС-003 увеличивается предельная удельная адсорбция ионов $\mathrm{Fe}^{3+}$, в особенности на сульфированном сорбенте БАКС-003. При этом практически все активные центры являются носителями катионообменных свойств. Особенно, катионообменные свойства проявляются в изменении отношения коэффициентов селективности сорбентов к ионам $\mathrm{Fe}^{3+}$ и спирта. В случае композита БАКС-003 по сравнению с БАКС-001, оно увеличивается примерно в 7.5 раз.

\section{Заключение}

Таким образом, выявлено, что полученные композиты проявляют довольно высокую сорбционную способность к органическим веществам дифильного характера. При этом модифицирование базового сорбента БАКС-001 сульфатом железа и, особенно серной кислотой, позволяет увеличить удельную поверхность, а, следовательно, сорбционную емкость. Высокая эффективность композитов при извлечении органических соединений из водных растворов позволяет считать перспективным использование их в системах кондиционирования воды.

\section{Список литературы}

1. Irani M., Amjadi M., Mousavian M.A. // Chemical Engineering Journal. 2011. Vol. 178. pp. 317-323.

2. Тихомирова Е.И., Веденеева Н.В., Нечаева О.В., Анохина Т.В. // Известия Самарского научного иентра Российской академии наук. 2016. Т. 18. №2 (3). С.812-816.

3. Котов В.В., Горелова Е.И., Горелов И.С., Данилова Г.Н. // Сорбичионые и хроматографические проиессы. 2014. Т.14. № 3. C.413-418.

4. Горелов И.С., Горелова Е.И Патент РФ №102195 Фильтрующий материал и фильтр для очистки воды - Опубл. В Бюл. №5, 2011.
5. Горелов И. С., Горелова Е.И., Котов В.В., Данилова Г.Н. // Материалы международной конференции «Теоретические и практические аспекты сорбционных и мембранных процессов» - Кемерово, 2014. С. 161-163.

6. Плисов Н.В., Матанцев В.А. Патент РФ №2130894, 1999.

7. Каррен П. Курс органической химии. Госхимиздат. Л. 1962. $1261 \mathrm{c.}$

8. Лабораторные работы и задачи по коллоидной химии. Под ред. Ю.Г. Фролова, А.С. Гродского. М. «Химия». 1986. 216 с. 


\section{References}

1. Irani M., Amjadi M., Mousavian M.A., and filter for water purification, In Bul. No 5, Chemical Engineering Journal, 2011, Vol. 178, 2011. pp. 317-323.

2. Tikhomirova E.I., Vedeneeva N.V., Nechaeva O.V., Anokhina T.V., Proceedings of the Samara Scientific Center of the Russian Academy of Sciences, 2016, Vol. 18, No 2 (3), pp. 812-816.

3. Kotov V.V., Gorelova E.I., Gorelov I.S., Danilova G.N., Sorbtsionnye i khromatograficheskie protsessy, 2014, Vol. 14, No 3, pp. 413418.

4. Gorelov I.S., Gorelova E.I. Patent of the Russian Federation №102195 Filtering material

Горелова Елена Ивановна - аспирантка 3го года обучения, Воронежский государственный аграрный университет имени императора Петра I, Воронеж, +7-919-188-62-58

Котов Владимир Васильевич - д.х.н., профессор кафедры химии, Воронежский государственный аграрный университет имени императора Петра I, Воронеж

Горелов Иван Стефанович - зав. лаборатории кафедры химии, Воронежский государственный аграрный университет имени императора Петра I, Воронеж

Данилова Галина Николаевна - старший преподаватель кафедры химии, Воронежский государственный аграрный университет имени императора Петра I, Воронеж

5. Gorelov I.S., Gorelova E.I., Kotov V.V., Danilova G.N., Proceedings of the International Conference «Theoretical and Practical Aspects of Sorption and Membrane Processes», Kemerovo, 2014, pp. 161-163.

6. Plisov N.V., Matantsev V.A. Patent of the Russian Federation, No 2130894, 1999.

7. Karren P., Course of Organic Chemistry, Goskhimizdat, L., 1962, 1261 p.

8. Laboratory works and tasks on colloid chemistry, Ed. by Frolova Yu.G., Grodsky A.S., M., «Chemistry», 1986, 216 p.

Gorelova Elena I. - the postgraduate student of the 3st year of studies, Voronezh State Agricultural University Named after The Emperor Peter the First, Voronezh, e-mail: elena2280@ya.ru;

Kotov Vladimir V. - the Doctor of the Chemistry Sciences, Prof. Chemistry Department, Voronezh State Agricultural University Named after The Emperor Peter the First, Voronezh;

Gorelov Ivan S. - Head of the Chemistry Laboratory of the Chemistry Department, Voronezh State Agricultural University Named after The Emperor Peter the First, Voronezh

Danilova Galina N. - Chemistry Senior Lecturer of the Chemistry Department, Voronezh State Agricultural University Named after The Emperor Peter the First, Voronezh, e-mail: dgn.vsau@mail.ru 